\title{
Exploration for reliable radiographic assessment method for hinge-like hypermobility at atlanto-occipital joint
}

\author{
Shinjiro Kaneko ${ }^{1,4} \cdot$ Ken Ishii $^{2,4} \cdot$ Kota Watanabe $^{2,4} \cdot$ Takashi Tsuji $^{3,4}$. \\ Masaya Nakamura $^{2,4} \cdot$ Morio Matsumoto $^{2,4} \cdot$ Yoshiyuki Yato $^{1,4}$ Takashi Asazuma ${ }^{1,4}$
}

Received: 11 December 2016 / Revised: 13 May 2017 / Accepted: 13 October 2017 / Published online: 20 October 2017

(c) The Author(s) 2017. This article is an open access publication

\begin{abstract}
Purpose Hinge-like hyper-mobility is occasionally observed at the atlanto-occipital (O-C1) joint. However, it has not been clear if this kind of hinge-like hyper-mobility at the O-C1 joint should be regarded as "pathologic", or referred to as "instability". To solve this issue, we aimed to establish a reliable radiographic assessment method for this specific type of O-C1 instability and figure out the "standard value" for the range of motion (ROM) of the $\mathrm{O}-\mathrm{C} 1$ joint. Methods To figure out the standard range of the O-C1 angle, we acquired magnetic resonance imaging (MRI) sagittal views of the cervical spine for 157 healthy volunteers [average: 37.4 year-old (yo)] without spine diseases, at neutral, maximum flexion and maximum extension positions.

Results The average value (AVE) for ROM of O-C1 angle was $9.91^{\circ}$. The standard value for ROM of O-C1 angle was calculated as $0^{\circ}-21^{\circ}$. There was no statistically significant gender difference. We also found that the older population ( $\geqq 40$ yo) significantly had a larger ROM of O-C1 angle (AVE: $11.72^{\circ}$ ) compared to the younger population (<40 yo) (AVE: $\left.8.99^{\circ}\right)$.

Conclusions We consider that hinge-like instability at $\mathrm{O}-\mathrm{C} 1$ joint, which cannot be assessed by measuring Powers ratio, can be assessed by measuring the range of $\mathrm{O}-\mathrm{C} 1$
\end{abstract}

Shinjiro Kaneko

ShinjiroKaneko@gmail.com

1 Department of Orthopaedic Surgery, National Hospital Organization Murayama Medical Center, Tokyo, Japan

2 Department of Orthopaedic Surgery, Keio University School of Medicine, Tokyo, Japan

3 Department of Orthopaedic Surgery, Fujita Health University Hospital, Toyoake, Japan

4 Keio Spine Research Group (KSRG), Tokyo, Japan angles using dynamic-MRI. Evaluation of O-C1 instability is important especially when we perform surgical treatment for diseases with upper cervical instability (such as retroodontoid pseudotumor). We consider that the current study provides important information in such a case.

Keywords Atlanto-occipital (O-C1) instability · Classification - Radiographic assessment method · Dynamic magnetic resonance imaging $\cdot \mathrm{O}-\mathrm{C} 1$ angle

\section{Introduction}

Atlanto-occipital (O-C1) instability [2, 3, 5, 7, 8, 11-14, 16, $19-23,25,26]$ is generally caused by trauma $[2,5,7,11-13$, $19,21,25]$. Non-traumatic O-C1 instability [3, 8, 14, 16, 20, $22,23,26]$, which is less common, is usually associated with rheumatoid arthritis (RA) $[16,20]$ or ankylosing spondylitis (AS) $[8,22]$. It can also be associated with Down syndrome [3, 11, 23] or infectious diseases [26].

It has been known that there are several types of O-C1 instability. We consider that $\mathrm{O}-\mathrm{C} 1$ instability can be classified into three types (Table 1). The first type is the anterior hyper-shift of the occiput (Type 1). This type has been the most-reported type and is usually accompanied with trauma $[2,5,7,11,12,19,21,25]$. The second type is characterized by posterior hyper-shift of the occiput (Type 2), which is often accompanied with RA [16, 20]. These two types of O-C1 instability have been termed as atlanto-occipital subluxation (AOS) $[2,5,7,8,12,14,16,20-23,25,26]$ and commonly been diagnosed by measuring Powers ratio [19].

Other than these two types, we sometimes observe hinge-like hyper-mobility at the $\mathrm{O}-\mathrm{C} 1$ joint (Type 3 ). This type of $\mathrm{O}-\mathrm{C} 1$ instability is occasionally accompanied with retro-odontoid pseudotumor (ROP) $[1,4,6,15,17,18,24$, 
Table 1 Our classification of O-C1 instability and each type's characteristics

\begin{tabular}{llll}
\hline & Type 1 & Type 2 & Type 3 \\
\hline $\begin{array}{l}\text { Type of O-C1 instability } \\
\begin{array}{l}\text { Representative case report in the } \\
\text { literatures }\end{array}\end{array}$ & Anterior hyper-shift of the occiput & $\begin{array}{l}\text { Posterior hyper-shift of the } \\
\text { occiput } \\
\text { Romanowski et al. [20] }\end{array}$ & $\begin{array}{c}\text { Hinge-like hyper-mobility at O-C1 } \\
\text { joint }\end{array}$ \\
$\begin{array}{l}\text { Adequate method for diagnosis } \\
\begin{array}{l}\text { Adequate tool(s) for diagnosis } \\
\text { Representative etiology }\end{array}\end{array}$ & $\begin{array}{l}\text { Powers ratio (> approx. 1) } \\
\text { Dynamic-MRI (or CT) or }(>) \text { Xp }\end{array}$ & $\begin{array}{l}\text { Powers ratio (< approx. 0.5) } \\
\text { Dynamic-MRI (or CT) or (>) Xp }\end{array}$ & $\begin{array}{c}\text { Our study (measuring ROM of } \\
\text { O-C1 angle) }\end{array}$ \\
& Mostly trauma & One of the consequences of RA & $\begin{array}{c}\text { Often accompanied with retro- } \\
\text { odontoid pseudo-tumor }\end{array}$ \\
\hline
\end{tabular}

27]. However, it has not been clear if this kind of hingelike hyper-mobility at the $\mathrm{O}-\mathrm{C} 1$ joint should be regarded as "pathologic", or referred to as "instability". If we can establish a reliable radiographic assessment method for $\mathrm{O}-\mathrm{C} 1$ instability and figure out the "standard value" for the range of motion (ROM) of the $\mathrm{O}-\mathrm{C} 1$ joint, we may be able to solve this issue.

\section{Materials and methods}

Using sagittal view $\mathrm{T} 2$ weighted-magnetic resonance imaging (MRI), we defined $\mathrm{O}-\mathrm{C} 1$ angle as the angle formed by (1) the line between the anterior and posterior borders of the foramen magnum, and (2) a line through the centers of the anterior and posterior arches of the atlas (Fig. 1a). The centers of the anterior and posterior arches were defined as the cross-point of the longest and shortest axis of the sagittal view of anterior and posterior arches. The structures of the bones are usually outlined by low intensity area in MRI T2-weighted images. This low intensity area sometimes cannot be distinguished from other attaching structures such as ligaments, so that the measurements were performed by selecting relatively high intensity area as the outlines of the bones.

To figure out the standard range of the $\mathrm{O}-\mathrm{C} 1$ angle, we acquired T2-weighted dynamic-MRI of the cervical spine for 157 healthy volunteers (22-65 years old (yso), average: 37.4 yso) without spine diseases, at neutral, maximum flexion and maximum extension positions (Fig. 1b-d). To make sure that the flexion and extension is at the person's
Fig. 1 Method for measuring $\mathrm{O}-\mathrm{C} 1$ angle. a We defined O-C1 angle as the angle formed by (1) the line between the anterior and posterior borders of the foramen magnum, and (2) a line through the centers of the anterior and posterior arches of the atlas and measured it using T2-weighted sagittal view MRI. b-d We acquired T2-weighted dynamic-MRI of the cervical spine at maximum flexion (b), neutral (c), and maximum extension positions (d) a

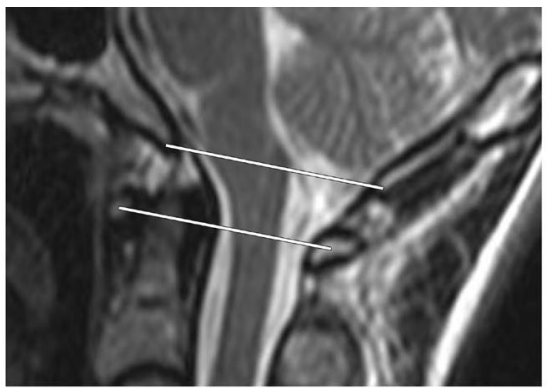

b

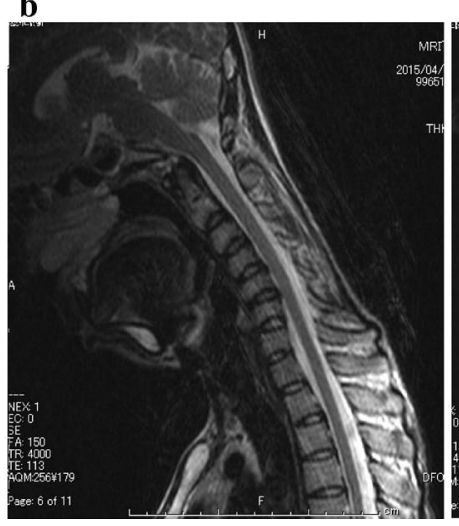

d

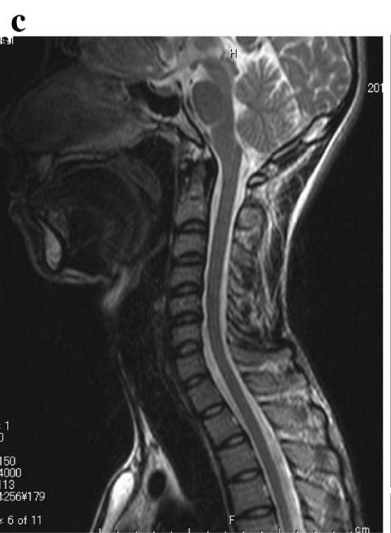

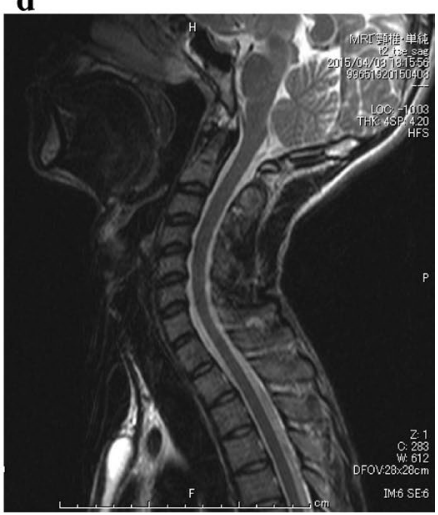


maximum, an assisting device was used to hold the person's head position.

Intra-observer reliability was assessed by performing the measurement once a day for 3 consecutive days, obtaining a total of three measurements. For intra-observer reliability assessment, 15 different samples were used. Inter-observer reliability was assessed with six surgeons including three board-certificated instructors in spinal surgery (instructors) and three under-training-spinal surgeons (fellows). For interobserver reliability assessment, 15 different samples and 45 images in total were used for each measurer to measure $\mathrm{O}-\mathrm{C} 1$ angle at 3 different positions in each sample. Interobserver and intra-observer reliability were estimated by calculating intra-class correlation coefficients (ICC) at 95\% confidence intervals using IBM SPSS statistics (version 24) software.

We calculated O-C1 ROM by subtracting the O-C1 angle at maximum extension from that of maximum flexion. Student $t$ test was used for statistical analysis in the comparative analyses.
All the process of the current study was reviewed and approved by the Institutional Review Board at our institute.

\section{Results}

We first evaluated the intra-observer and inter-observer reliability of our measurement method of the $\mathrm{O}-\mathrm{C} 1$ angle. The data of intra-observer reliability is shown in Table 2A. While ICC $(1,3)$ was 0.996 , $\operatorname{ICC}(1,1)$ was 0.989 indicating that data acquired by single measurement has an excellent enough reliability. Considering this data, we used data from single measurements in the following inter-observer reliability analysis.

As mentioned, inter-observer reliability was assessed by six surgeons including three board-certificated instructors in spinal surgery (instructors) and three under-training-spinal surgeons (fellows). Assessment was performed in all three different positions: neutral, maximum flexion and maximum extension positions.

Table 2 Intra-observer reliability and inter-observer reliability analyses of O-C1 angle measurement

\begin{tabular}{|c|c|c|c|}
\hline \multicolumn{4}{|l|}{ A. Intra-observer reliability } \\
\hline \multicolumn{2}{|l|}{ Intra-observer reliability } & \multirow{2}{*}{$\begin{array}{l}95 \% \text { confidence interval } \\
0.973-0.996\end{array}$} & \multirow{2}{*}{$\frac{p \text { value }}{<0.01}$} \\
\hline $\operatorname{ICC}(1,1)$ & 0.989 & & \\
\hline $\operatorname{ICC}(1,3)$ & 0.996 & $0.991-0.999$ & $<0.01$ \\
\hline \multicolumn{4}{|c|}{ B: Inter-observer reliability analysis of board-certificated instructors in spinal surgery (instructors) } \\
\hline Inter-observer reliability (instructors) & & $95 \%$ confidence interval & $p$-value \\
\hline \multicolumn{4}{|l|}{ Neutral position } \\
\hline $\operatorname{ICC}(2,1)$ & 0.933 & $0.850-0.975$ & $<0.01$ \\
\hline $\operatorname{ICC}(2,3)$ & 0.976 & $0.944-0.991$ & $<0.01$ \\
\hline \multicolumn{4}{|l|}{ Maximum flexion position } \\
\hline $\mathrm{ICC}(2,1)$ & 0.973 & $0.938-0.990$ & $<0.01$ \\
\hline $\mathrm{ICC}(2,3)$ & 0.991 & $0.978-0.997$ & $<0.01$ \\
\hline \multicolumn{4}{|l|}{ Maximum extension position } \\
\hline $\operatorname{ICC}(2,1)$ & 0.959 & $0.907-0.985$ & $<0.01$ \\
\hline $\operatorname{ICC}(2,3)$ & 0.986 & $0.967-0.995$ & $<0.01$ \\
\hline \multicolumn{4}{|c|}{ C: Inter-observer reliability analysis of under-training-spinal surgeons (fellows) } \\
\hline Inter-observer reliability (fellows) & & $95 \%$ confidence interval & $p$-value \\
\hline \multicolumn{4}{|l|}{ Neutral position } \\
\hline $\operatorname{ICC}(2,1)$ & 0.972 & $0.936-0.990$ & $<0.01$ \\
\hline $\operatorname{ICC}(2,3)$ & 0.990 & $0.978-0.997$ & $<0.01$ \\
\hline \multicolumn{4}{|l|}{ Maximum flexion position } \\
\hline $\operatorname{ICC}(2,1)$ & 0.915 & $0.814-0.968$ & $<0.01$ \\
\hline $\operatorname{ICC}(2,3)$ & 0.970 & $0.929-0.989$ & $<0.01$ \\
\hline \multicolumn{4}{|l|}{ Maximum extension position } \\
\hline $\operatorname{ICC}(2,1)$ & 0.944 & $0.870-0.979$ & $<0.01$ \\
\hline $\operatorname{ICC}(2,3)$ & 0.981 & $0.953-0.993$ & $<0.01$ \\
\hline
\end{tabular}


Table 3 O-C1 angle of the whole population of the study

\begin{tabular}{lllll}
\hline $\begin{array}{l}\text { O-C1 angle } \\
\left({ }^{\circ}\right)\end{array}$ & $\begin{array}{l}\text { At neutral } \\
\text { position }\end{array}$ & $\begin{array}{l}\text { At } \\
\text { maximum } \\
\text { flexion } \\
\text { position }\end{array}$ & $\begin{array}{l}\text { At maximum } \\
\text { extension } \\
\text { position }\end{array}$ & ROM \\
\hline $\begin{array}{c}\text { Overall } \\
(n=157)\end{array}$ & $5.06 \pm 0.48$ & $9.27 \pm 0.49$ & $-0.64 \pm 0.489 .91 \pm 0.45$ \\
\hline
\end{tabular}

$\mathrm{AVE} \pm \mathrm{SEM}$ is presented in the table. When we regard the standard value for ROM of $\mathrm{O}-\mathrm{C} 1$ angle as the value within the range of $\pm 2 \mathrm{SD}$, it was calculated as $0^{\circ}-21^{\circ}$

The data of inter-observer reliability acquired from instructors are shown in Table 2B. At neutral position, $\operatorname{ICC}(2,1)$ was 0.933 and $\operatorname{ICC}(2,3)$ was 0.976 . At maximum flexion position, $\operatorname{ICC}(2,1)$ was 0.973 and $\operatorname{ICC}(2,3)$ was 0.991 . At maximum extension position, $\operatorname{ICC}(2,1)$ was 0.959 and $\operatorname{ICC}(2,3)$ was 0.986 . These values indicate that these measurements have excellent inter-observer reliability at all three positions. The data of inter-observer reliability acquired from fellows are shown in Table $2 \mathrm{C}$. These values also indicate that the measurements have excellent inter-observer reliability at all three positions.

Taken together, we considered that this measurement method of O-C1 angle is reliable enough to explore the "standard value" for the range of motion (ROM) of the O-C1 joint with good reproducibility and feasibility.

To figure out the standard range of the $\mathrm{O}-\mathrm{C} 1$ angle, we measured O-C1 angle for 157 healthy volunteers at neutral, maximum flexion and maximum extension positions.
The average value (AVE) of the whole population of the study for O-C1 angle at neutral, maximum flexion and maximum extension positions was $5.06^{\circ}, 9.27^{\circ}$ and $-0.64^{\circ}$, respectively (Table 3 ). AVE for ROM of the O-C1 angle was calculated as $9.91^{\circ}$ (Table 3). When we regard the standard value for $\mathrm{ROM}$ of $\mathrm{O}-\mathrm{C} 1$ angle as the value within the range of $\pm 2 \mathrm{SD}$, it was calculated as $0^{\circ}-21^{\circ}$.

We also examined whether there is a significant difference between males and females. Average age of males and females was 36.32 and 39.58 yo, respectively. There was no statistically significant difference. AVE for ROM of O-C1 angle was $10.07^{\circ}$ in males and $9.60^{\circ}$ in females (Table 4). There was no statistically significant difference between the two groups.

Next, we examined whether there is a significant difference between the older population ( $\geqq 40$ yo) and the younger population $(<40$ yo). We found that the older population significantly had a larger ROM of O-C1 angle (AVE: $11.72^{\circ}$ ) compared to the younger population (AVE: $8.99^{\circ}$ ) $(p=0.0038)$ (Table 5).

\section{Discussion}

The standard ROM of the $\mathrm{O}-\mathrm{C} 1$ joint has not been clear partly because the precision of measurements obtained from dynamic-X-ray films, especially those using occipital landmarks is limited by the relatively poor resolution. We consider that Type 3 O-C1 instability, which cannot be assessed by measuring Powers ratio [19], can be assessed by measuring the range of $\mathrm{O}-\mathrm{C} 1$ angles using dynamic-MRI. In
Table 4 O-C1 angle of males and females

\begin{tabular}{llllr}
\hline O-C1 angle $\left({ }^{\circ}\right)$ & At neutral position & $\begin{array}{l}\text { At maximum flex- } \\
\text { ion position }\end{array}$ & $\begin{array}{l}\text { At maximum exten- } \\
\text { sion position }\end{array}$ & ROM \\
\hline Males $(n=105)$ & $5.89 \pm 0.59$ & $9.96 \pm 0.57$ & $-0.10 \pm 0.60$ & $10.07 \pm 0.56$ \\
Females $(n=52)$ & $3.23 \pm 0.75$ & $7.88 \pm 0.88$ & $-1.71 \pm 0.77$ & $9.60 \pm 0.77$ \\
\hline
\end{tabular}

AVE \pm SEM is presented in the table. No statistically significant difference was found between the two groups

\begin{tabular}{lllll}
\hline O-C1 angle $\left(^{\circ}\right)$ & At neutral position & $\begin{array}{l}\text { At maximum } \\
\text { flexion position }\end{array}$ & $\begin{array}{l}\text { At maximum } \\
\text { extension position }\end{array}$ & ROM \\
\hline $\begin{array}{c}\text { Younger population } \\
(<40 \text { yso })(n=104)\end{array}$ & $4.70 \pm 0.55$ & $8.58 \pm 0.56$ & $-0.41 \pm 0.58$ & $8.99 \pm 0.49$ \\
$\begin{array}{l}(73 \text { males and } 31 \\
\text { females })\end{array}$ & & & & \\
$\begin{array}{c}\text { Older population }(\geqq 40 \\
\text { yso }(n=53)(32 \text { males }\end{array}$ & $5.60 \pm 0.92$ & $10.64 \pm 0.91$ & $-1.08 \pm 0.83$ & $11.72 \pm 0.90^{*}$ \\
and 21 females $)$ & & & & \\
\hline
\end{tabular}

$\mathrm{AVE} \pm \mathrm{SEM}$ is presented in the table. The older population significantly had a larger ROM of O-C1 angle compared to the younger population $\left({ }^{*} p=0.0038\right)$
Table 5 O-C1 angle of the older population ( $\geqq 40$ yso) and the younger population $(<40$ yso) 
addition, assessment using dynamic-MRI has an advantage that it can be performed without exposure to radiation.

Dvorak et al. examined age and gender related standard motion of the cervical spine. By developing a clinical method for measuring three-dimensional motion of the cervical spine using a specific device, they obtained the standard values for passive examinations of flexion-extension, lateral bending, rotation, rotation out of maximum flexion, and rotation out of maximum extension and analyzed them for each gender in a group of 150 normal subjects. Results of rotation out of maximum flexion suggest and supported their earlier conclusions that the rotation of the $\mathrm{C} 1-\mathrm{C} 2$ segment does not decrease with age, but rather increases slightly. They concluded that it may be the compensation for the overall decreased motion in the lower segments [10].

In this study, we found that the older population ( $\geqq 40$ yo) significantly had a larger ROM of O-C1 angle compared to the younger population $(<40 \mathrm{yo})$. We consider that this also may be the compensation for the overall decreased motion in the lower segments.

In the craniocervical joint, the alar and transverse ligaments provide much of the stability in the healthy spine. These ligaments can be damaged by a high-energy deceleration force that causes hyperextension-flexion. Chaput et al. performed radiographic analysis to detect these traumatic ligamentous injuries [5]. The degenerative change on the $\mathrm{O}-\mathrm{C} 1$ joint may also affect the $\mathrm{O}-\mathrm{C} 1$ ligaments and its joint stability. The alar ligament restrains rotation of the upper cervical spine, whereas the transverse ligament restricts flexion as well as anterior displacement of the atlas [9]. A lesion in one or both structures can produce damage to the neural structures and/or cause pain. Dvorak et al. investigated the possible role of each of these ligaments by a mechanical and histologic study of the upper cervical spine. Using the bone-ligament-bone complex of the alar and transverse ligaments, they performed a uniaxial mechanical testing in the specimens. The result reported that the transverse ligaments had greater strength in vitro strength compared with the alar ligaments. They also revealed a mainly collagenous nature in these ligaments through histologic analysis and mentioned that clinical evidence (broken odontoid processes) suggests that the transverse ligament is strong enough to withstand physiologic loads. They also mentioned that the alar ligament, on the other hand, due to its lower strength and its axial direction of loading, might be prone to injury and therefore require stabilization of the appropriate vertebra more often than normally assumed [9]. Future detailed analysis is necessary to elucidate the degenerative changes in $\mathrm{O}-\mathrm{C} 1$ joint in stability occurring in the older population.

ROP is commonly associated with upper cervical instability and surgical treatment for ROP includes arthrodesis. Historically, ROP had been well-known to be accompanied with atlantoaxial subluxation (AAS). However, Chikuda et al. and Tanaka et al. suggested that AAS does not accompany ROP in some cases $[6,24]$. Yet, the underlying mechanism for ROP formation without AAS has not been well-elucidated. ROP is also reported to be associated with diffuse idiopathic skeletal hyperostosis (DISH) $[4,15]$ at times. Taken together, O-C1 instability has been thought to be one of the possible causes of ROP without AAS. However, there has been no clear evidence of it due to the lack of reliable radiographic assessment methods for $\mathrm{O}-\mathrm{C} 1$ instability. When performing arthrodesis for ROP, evaluation of O-C1 instability is important to decide if the fusion range should include O-C1 [1, 4, 17, 27]. Commonly, the type of O-C1 instability accompanied with ROP is the hinge-like hypermobility at the $\mathrm{O}-\mathrm{C} 1$ joint. It has not been clear whether this kind of hinge-like hyper-mobility at the $\mathrm{O}-\mathrm{C} 1$ joint should be regarded as "pathologic", or referred to as "instability".

In this study, we proposed a reliable radiographic assessment method for Type $3 \mathrm{O}-\mathrm{C} 1$ instability and figured out the "standard value" for the range of motion (ROM) of the O-C1 joint. We consider that the current study provides important information for such a case.

As mentioned, ROP sometimes is associated with DISH $[4,15]$. O-C1 instability, as the compensation for the overall decreased motion in the lower segments, may be the underlying mechanism of ROP formation in cases associated with DISH. Future study using the radiographic method we proposed in the current study may elucidate the underlying mechanism of ROP formation with DISH, or those without AAS.

$\mathrm{O}-\mathrm{C} 1$ instability can be also associated with rheumatoid arthritis (RA) [16, 20] ankylosing spondylitis (AS) [8, 22], Down syndrome [3,11,23] or infectious diseases [26], as mentioned. Future study using the radiographic method we proposed in the current study may also contribute to clarify the underlying mechanism of these diseases.

Acknowledgements We gratefully acknowledge Dr. Yuji Nishiwaki, Dr. Hitoshi Kono, Dr. Akio Iwanami, Dr. Junichi Yamane, Dr. Takashi Kato, Dr. Taro Umezu, Dr. Yasuhiro Kamata and Dr. Takahiro Ishizaka, who assisted this study. We also gratefully acknowledge those who accepted to be healthy volunteers in this study, those who performed MRI scanning and all other people who involved in this study.

\section{Compliance with ethical standards}

Conflict of interest No conflict of interest to declare.

Open Access This article is distributed under the terms of the Creative Commons Attribution 4.0 International License (http://creativecommons.org/licenses/by/4.0/), which permits unrestricted use, distribution, and reproduction in any medium, provided you give appropriate credit to the original author(s) and the source, provide a link to the Creative Commons license, and indicate if changes were made. 


\section{References}

1. Barbagallo GM, Certo F, Visocchi M et al (2013) Disappearance of degenerative, non-inflammatory, retro-odontoid pseudotumor following posterior $\mathrm{C} 1-\mathrm{C} 2$ fixation: case series and review of the literature. Eur Spine J 22:S879-S888

2. Bisson E, Schiffern A, Daubs MD et al (2010) Combined occipital-cervical and atlantoaxial disassociation without neurologic injury: case report and review of the literature. Spine 35:E316-E321

3. Brooke DC, Burkus JK, Benson DR (1987) Asymptomatic occipito-atlantal instability in down syndrome (trisomy 21). Report of two cases in children. J Bone Joint Surg Am 69:293-295

4. Castro-Castro J, Castro-Bouzas D, Pinzón-Millán A et al (2014) Retro-odontoid pseudotumor in diffuse idiopathic skeletal hyperostosis. Neurocirugia 25:25-28

5. Chaput CD, Walgama J, Torres E et al (2011) Defining and detecting missed ligamentous injuries of the occipitocervical complex. Spine 36:709-714

6. Chikuda H, Seichi A, Takeshita K et al (2009) Radiographic analysis of the cervical spine in patients with retro-odontoid pseudotumors. Spine (Phila Pa 1976) 34:E110-E114

7. Cooper Z, Gross JA, Lacey JM et al (2010) Identifying survivors with traumatic craniocervical dissociation: a retrospective study. J Surg Res 160:3-8

8. Davidson RI, Tyler HR (1974) Bulbar symptoms and episodic aphonia associated with atlanto-occipital subluxation in ankylosing spondylitis. J Neurol Neurosurg Psychiatry 37:691-695

9. Dvorak J, Schneider E, Saldinger P et al (1988) Biomechanics of the craniocervical region: the alar and transverse ligaments. $J$ Orthop Res 6:452-461

10. Dvorak J, Antinnes JA, Panjabi M et al (1992) Age and gender related normal motion of the cervical spine. Spine 17:S393-S398

11. Georgopoulos G, Pizzutillo PD, Lee MS (1987) Occipito-atlantal instability in children. A report of five cases and review of the literature. J Bone Joint Surg Am 69:429-436

12. Hamai S, Harimaya K, Maeda T et al (2006) Traumatic atlantooccipital dislocation with atlantoaxial subluxation. Spine 31:E421-E424

13. Hanson JA, Deliganis AV, Baxter AB et al (2002) Radiologic and clinical spectrum of occipital condyle fractures: retrospective review of 107 consecutive fractures in 95 patients. Am J Roentgenol 178:1261-1268
14. Hettiaratchy S, Ning C, Sabin I (1998) Nontraumatic atlantooccipital and atlantoaxial rotatory subluxation: case report. Neurosurgery 43:164-165

15. Jun BY, Yoon KJ, Crockard A (2002) Retro-odontoid pseudotumor in diffuse idiopathic skeletal hyperostosis. Spine (Phila Pa 1976) 27:E266-E270

16. Konishi A, Higo R, Nito T et al (2003) A case report of unilateral hypoglossal neuroparalysis resulting from horizontal subluxation in the atlantooccipital joint due to rheumatoid arthritis. ORL J Otorhinolaryngol Relat Spec 65:306-309

17. Lagares A, Arrese I, Pascual B et al (2006) Pannus resolution after occipitocervical fusion in a non-rheumatoid atlanto-axial instability. Eur Spine J 15:366-369

18. Matsumoto T, Takada S, Tsujimoto K et al (2006) Enlarging retroodontoid pseudotumor after expanding cervical laminoplasty in the presence of kyphosis. Spine J 6:228-232

19. Powers B, Miller MD, Kramer RS et al (1979) Traumatic anterior atlanto-occipital dislocation. Neurosurgery 4:12-17

20. Romanowski CA, Nisar M, Nakielny RA (1995) Atlanto-occipital subluxation in rheumatoid arthritis demonstrated by magnetic resonance imaging. Br J Rheumatol 34:787-789

21. Shamoun JM, Riddick L, Powell RW (1999) Atlanto-occipital subluxation/dislocation: a "survivable" injury in children. Am Surg 65:317-320

22. Shim SC, Yoo DH, Lee JK et al (1998) Multiple cerebellar infarction due to vertebral artery obstruction and bulbar symptoms associated with vertical subluxation and atlanto-occipital subluxation in ankylosing spondylitis. J Rheumatol 25:2464-2468

23. Stein SM, Kirchner SG, Horev G et al (1991) Atlanto-occipital subluxation in Down syndrome. Pediatr Radiol 21:121-124

24. Tanaka S, Nakada M, Hayashi Y et al (2010) Retro-odontoid pseudotumor without atlantoaxial subluxation. J Clin Neurosci 17:649-652

25. Theodore N, Aarabi B, Dhall SS et al (2013) The diagnosis and management of traumatic atlanto-occipital dislocation injuries. Neurosurgery 72:114-126

26. Tsunoda K, Iizuka H, Sorimachi $Y$ et al (2011) Atlanto-axial subluxation after pyogenic spondylitis of the atlanto-occipital joint. Eur Spine J 20:S253-S257

27. Yamazaki M, Okawa A, Mannoji C et al (2009) C1 dome-like laminotomy and posterior $\mathrm{C} 1-\mathrm{C} 2$ polyaxial screw-rod fixation for a patient with cervical myelopathy due to a retro-odontoid pseudotumor. J Clin Neurosci 16:99-103 